\title{
Conservative management of spontaneous rupture of the urinary bladder: reply by the authors
}

\author{
Ismaiel Abu Mahfouz • Tim Sayer • Christian Phillips
}

Published online: 11 June 2011

(C) The International Urogynecological Association 2011

\section{Dear Editor,}

Pelvic organ prolapse (POP) is thought to be associated with voiding dysfunction [1]. We agree with Dr. Ho [2] that POP probably contributed towards the bladder rupture. The irreducible POP may have caused obstructed voiding with subsequent increase in intravesical pressure with eventual rupture of an area of low resistance such as the bladder diverticulum. While the woman in our case [3] reported a 3day history of abdominal pain and irreducible POP and 1 day urinary retention, we believed at presentation that she may have had a degree of voiding dysfunction that she was not aware of. This in turn caused the intraperitoneal rupture, hence the abdominal pain which preceded the urine retention. We also believe that the size of the rupture had increased in size over the next few days and may explain why she did not void for a day prior to the consultation as the increase in the size of the rupture further reduced the flow resistance.

While the woman in our case always maintained a normal temperature, at presentation, the white blood cell count was $4.4 \times 10^{3} / \mathrm{ml}$ (normal range, $4.0-11.0 \times 10^{9} / \mathrm{L}$ ) and C-reactive protein (CRP) was $38 \mathrm{mg} / \mathrm{L}$ (normal, $<5 \mathrm{mg} / \mathrm{L}$ ). Later she developed deterioration in the inflammatory markers (WCC, $18.8 \times 10^{3} / \mathrm{ml}$ and CRP, 212), which was normalised after the intravenous antibiotics. We performed a CT scan as part of the investigation of the lower abdominal pain; this showed a rather small amount of fluid collection in the pelvis which is not in keeping with the clinical picture of 1-day urine retention, it is probably due to peritoneal fluid absorption.
We acknowledge, however, the emergency nature of the intraperitoneal rupture and the potential subsequent serious complication [4]. We agree that early surgical management with drainage, debridement and repair is often necessary, however, once the diagnosis was confirmed, the woman had shown significant clinical and biochemical improvement and the multidisciplinary team decided on conservative management. The woman was kept under close observation for any signs of deterioration. Urinary bladder ruptures managed conservatively had been shown to be more likely to recur [5], this may reflect differences in the healing between primary and secondary intention or might be due to failure to correct persisting risk factors for recurrence.

\section{References}

1. Coates KW, Harris RL, Cundiff GW, Bump RC (1997) Uroflowmetry in women with urinary incontinence and pelvic organ prolapse. Br J Urol 80(2):217-221

2. Ho CCK (2011) Conservative management of spontaneous rupture of the urinary bladder: comment. Int Urogynecol J. doi:10.1007/ s00192-011-1478-0

3. Abu Mahfouz I, Sayer T, Phillips C (2011) Conservative management of spontaneous rupture of the urinary bladder. Int Urogynecol $\mathrm{J}$ 22:629-631. doi:10.1007/s00192-010-1319-6

4. Saleem MA, Mahmoud AM, Gopinath BR (2009) Spontaneous urinary bladder rupture: a rare differential for lower abdominal pain in a female patient. Singapore Med J 50(12):e410-e411

5. Kaneko T, Nozawa T, Owari Y et al (2000) Recurrent spontaneous rupture of the urinary bladder: a case report. Hinyokika Kiyo 46 (2):137-139

I. A. Mahfouz $(\bowtie) \cdot$ T. Sayer $\cdot$ C. Phillips

Obstetrics and Gynaecology, North Hampshire Hospital,

Aldermaston Road, Basingstoke,

Hampshire, UK

e-mail: ismaiel_khr@yahoo.com 